\title{
Исследование встроенных электрических полей на интерфейсе GaSe/GaAs методом спектроскопии фотоотражения
}

\author{
(С) О.С. Комков ${ }^{1}$, С.А. Хахулин ${ }^{1}$, Д.Д. Фирсов ${ }^{1}$, П.С. Авдиенко ${ }^{2}$, И.В. Седова ${ }^{2}$, С.В. Сорокин ${ }^{2}$ \\ ${ }^{1}$ Санкт-Петербургский государственный электротехнический университет „ЛЭТИ“, \\ 197376 Санкт-Петербург, Россия \\ 2 Физико-технический институт им. А.Ф. Иоффре Российской академии наук, \\ 194021 Санкт-Петербург, Россия \\ E-mail: okomkov@yahoo.com
}

Поступила в Редакцию 27 апреля 2020 г. В окончательной редакции 20 мая 2020 г. Принята к публикации 20 мая 2020 г.

\begin{abstract}
При молекулярно-пучковой эпитаксии $\mathrm{GaSe}$ на подложках $\mathrm{GaAs}(001)$ на гетероинтерфейсе $\mathrm{GaSe} / \mathrm{GaAs}$ возникают встроенные электрические поля, о наличии которых свидетельствуют наблюдаемые в спектрах фотоотражения осцилляции Франца-Келдыша. Различные значения напряженностей этих полей (от 9.8 до 17.6 кB/cм) могут быть связаны как с диффузией атомов Se в подложку (буферный слой) GaAs, так и с формированием при эпитаксиальном росте переходных субмонослоев. На интерфейсе структур, выращенных на подложках $\operatorname{GaAs}(111) \mathrm{B}$ и $\mathrm{GaAs}(112)$, встроенные поля не наблюдаются, что может быть объяснено меньшей эффективностью проникновения Se в подложку с вышеуказанными ориентациями по сравнению c $\operatorname{GaAs}(001)$.
\end{abstract}

Ключевые слова: GaSe, слоистые полупроводники, модуляционная оптическая спектроскопия, молекулярно-пучковая эпитаксия, фотоотражение.

DOI: 10.21883/FTP.2020.10.49936.9421

\section{1. Введение}

Уникальные структурные, электрические и оптические свойства полупроводниковых соединений с экстремальной двумерностью (к которым относятся халькогениды постпереходных металлов - GaSe, InSe и др.) представляют большой интерес для исследователей [1-3]. $\mathrm{B}$ частности, GaSe является перспективным материалом для изготовления полевых транзисторов и высокоэффективных фотоприемников [4-7].

Было показано, что на основе одиночного слоя двумерного GaSe возможно создать высокочувствительный фотоприемник, способный детектировать слабые сигналы порядка нВт в ультрафиолетовой и видимой областях оптического спектра (250-600 нм) с максимумом чувствительности на длине волны $254 \mathrm{нм}$ [7]. Однако в большинстве перечисленных выше работ были использованы либо эксфолиированные „чешуйки“ $\mathrm{GaSe}$, либо небольшие по площади образцы, полученные методами химического осаждения из газовой фазы. Метод молекулярно-пучковой эпитаксии (МПЭ), потенциально позволяющий реализовать получение высококачественных 2D-кристаллов большой площади на коммерчески доступных подложках, находится пока на стадии развития [8].

Сильная анизотропия транспортных, механических и оптических свойств GaSe является следствием его слоистой кристаллической структуры. Объемные кристаллы GaSe представляют собой набор вертикально упорядоченных тетраслоев (ТC) связанных между собой посредством слабых сил Ван-дер-Ваальса. Каждый ТС толщиной $\sim 0.8 \mathrm{Hм}$ состоит из четырех ковалентносвязанных атомных слоев Se-Ga-Ga-Se [9]. Следует отметить, что GaSe может кристаллизоваться в различных политипах, отличающихся друг от друга последовательностью укладки ТС: с гексагональной $(\beta-, \varepsilon$ и $\delta$-политип) или ромбоэдрической ( $\gamma$-политип) кристаллической решеткой [9]. Было показано, что слои $\mathrm{GaSe}$, выращенные методом МПЭ, как правило, соответствуют $\varepsilon$ - или $\gamma$-политипу $[8,10,11]$. Из-за слабых связей между слоями эпитаксия GaSe по механизму Вандер-Ваальса [12] на подложках $\operatorname{GaAs}(001)$ реализуется при температурах подложки $T_{S} \sim 400^{\circ} \mathrm{C}$, в то время как при $T_{S}>500^{\circ} \mathrm{C}$ зарождение GaSe на поверхности $\mathrm{GaAs}(001)$ происходит через формирование переходных субмонослоев с образованием химических связей с подложкой $[8,10,13]$.

Цель данной работы - исследование методом фотоотражения (ФО) степени взаимодействия эпитаксиального слоя GaSe c подложкой GaAs в зависимости от еe кристаллографической ориентации, наличия гомоэпитаксиального буферного слоя GaAs и режимов МПЭ.

Метод ФО является разновидностью модуляционной оптической спектроскопии, которая эффективно используется не только для изучения электронной структуры объемных материалов, но и для исследования границ раздела контактирующих полупроводников. Метод ФО позволяет измерять значение напряженности встроенного электрического поля и электрического потенциала [14], находить концентрацию свободных носителей заряда [15], определять положение уровня Ферми на поверхности полупроводника [16]. 
Таблица 1. Параметры МПЭ и толщины исследованных слоев $\mathrm{GaSe} / \mathrm{GaAs}$

\begin{tabular}{|c|c|c|c|c|c|c|}
\hline Структура & $\begin{array}{c}\text { Ориентация } \\
\text { подложки } \\
\text { GaAs }\end{array}$ & $\mathrm{Se} / \mathrm{Ga}^{*}$ & $T_{S},{ }^{\circ} \mathrm{C}$ & $\begin{array}{c}\text { Время } \\
\text { осаждения } \\
t, \text { мин }\end{array}$ & $\begin{array}{c}\text { Толщина } \\
\text { слоя/скорость } \\
\text { осаждения }\end{array}$ & Примечания \\
\hline$A$ & \multirow{4}{*}{$(001)$} & $1.3 / 1.4$ & 450 & 60 & $\begin{array}{c}240 \text { нм } \\
4 \text { нм/Мин }\end{array}$ & - \\
\hline$B$ & & $1.7 / 1.8$ & 470 & 113 & $\begin{array}{c}150 \mathrm{Hм} \\
1.3 \mathrm{Hм} / \mathrm{Mин}\end{array}$ & - \\
\hline$C$ & & $2.4 / 2.6$ & 400 & 154 & $\begin{array}{c}200 \mathrm{Hм} \\
1.3 \mathrm{Hм} / \mathrm{Mин}\end{array}$ & - \\
\hline$E$ & & $1.5 / 1.3$ & $400 / 500$ & 113 & $\begin{array}{c}300 \mathrm{Hм} \\
5 \mathrm{Hм} / \mathrm{мин} \\
\\
360 \mathrm{Hм} \\
3 \mathrm{Hм} / \mathrm{Mин}\end{array}$ & $\begin{array}{c}\text { Буферный слой } \\
\text { GaAs - } 200 \text { нм } \\
\text { Буферный слой } \\
\text { GaAs - } 200 \text { нм; } \\
\text { двухстадийный } \\
\text { режим МПЭ }\end{array}$ \\
\hline$F$ & \multirow[t]{2}{*}{ (111)B } & $\sim 6$ & 400 & 120 & $\begin{array}{c}60 \mathrm{Hм} \\
0.5 \mathrm{Hм} / \mathrm{мин}\end{array}$ & $\begin{array}{c}\text { Выдержка } \\
\text { поверхности } \mathrm{GaAs} \\
4 \text { мин в потоке } \mathrm{Se} \\
\text { перед инициацией } \\
\text { роста GaSe }\end{array}$ \\
\hline$G$ & & $1.6 / 1.4$ & $400 / 500$ & 136 & $\begin{array}{c}170 \mathrm{нм} \\
\sim 1.2 \mathrm{Hм} / \mathrm{мин}\end{array}$ & $\begin{array}{c}\text { Двухстадийный } \\
\text { режим МПЭ }\end{array}$ \\
\hline$H$ & (112) & $1.1 / 1.2$ & 400 & 60 & $\begin{array}{c}86 \mathrm{Hм} \\
1.4 \mathrm{HM} / \mathrm{Mин}\end{array}$ & - \\
\hline
\end{tabular}

Примечание. * Приведены расчетные соотношения падающих атомов $\mathrm{Se} / \mathrm{Ga}$ на поверхности роста с учетом температуры эпитаксиального роста $\left(T_{S}\right)$ и температуры зоны разложения клапанного источника Se согласно [8].

Выделяются следующие основные режимы ФО [17]:

- слабополевой, когда встроенное электрическое поле имеет малое значение напряженности. При этом в спектре ФО наблюдается единичная осцилляция, соответствующая оптическому переходу „валентная зоназона проводимости“;

- среднеполевой, при котором в спектре ФО наблюдаются затухающие осцилляции, называемые осцилляциями Франца-Келдыша (ОФК). В данном режиме напряженность поля возможно определить из экспериментально измеренного спектра.

Таким образом, анализируя сигнал ФО от приинтерфейсной области GaAs, можно сделать выводы о характере взаимодействия GaSe с подложкой.

\section{2. Методика эксперимента}

Все слои $\mathrm{GaSe}$, исследованные в данной работе, были выращены методом МПЭ в двухкамерной установке STE3526 (SemiTEq, Россия) на подготовленных для эпитаксии („ерi-ready“) односторонне полированных полуизолирующих подложках $\mathrm{GaAs}(001)$ и $\mathrm{GaAs}(111) \mathrm{B}$. Для полуизолирующих подложек $\mathrm{GaAs}(112)$ с двухсторонней полировкой проводилась предварительная химическая подготовка поверхности, выполненная по стандартной методике и включающая в себя травление в растворе
$\mathrm{H}_{2} \mathrm{SO}_{4}: \mathrm{H}_{2} \mathrm{O}_{2}: \mathrm{H}_{2} \mathrm{O}(4: 1: 1)$ для удаления как механических нарушений поверхности, так и толстого оксидного слоя, сформировавшегося на поверхности подложки в результате ее хранения.

В качестве источников молекулярных пучков использовались стандартный элементный источник $\mathrm{Ga}$ и источник Se c высокотемпературным разложителем и клапаном (Veeco, CША) с температурой зоны разложения $T_{\mathrm{Se}}(\mathrm{cr})=500-600^{\circ} \mathrm{C}$. Отношение потоков $\mathrm{Se} / \mathrm{Ga}$ контролировалось посредством измерения эквивалентных давлений в пучках (ЭДП, ВЕР — beam equivalent pressure) $P_{\mathrm{Se}}(\mathrm{BEP}) / P_{\mathrm{Ga}}(\mathrm{BEP})$ в положении роста при помощи ионизационного датчика Байярда-Альперта. Рост $\mathrm{GaSe}$ инициировался либо одновременным открытием потоков $\mathrm{Ga}$ и $\mathrm{Se}$ на поверхность GaAs, либо после выдержки поверхности $\mathrm{GaAs}$ в потоке $\mathrm{Se}$.

Образцы $A, B, C, H$ были выращены непосредственно на подложках $\mathrm{GaAs}$, отожженных в отсутствие потока As при $T_{S} \sim 580-600^{\circ} \mathrm{C}$ в камере роста соединений $\mathrm{A}^{\mathrm{III}} \mathrm{B}^{\mathrm{VI}}$. В образцах $D$ и $E$ слои GaSe были осаждены на поверхности нелегированного буферного слоя GaAs толщиной 200 нм, выращенного в камере роста полупроводниковых соединений на основе $\mathrm{A}^{\mathrm{III}} \mathrm{B}^{\mathrm{V}}$, а затем переданного в камеру роста соединений $\mathrm{A}^{\mathrm{III}} \mathrm{B}^{\mathrm{VI}}$ по высоковакуумному трубопроводу.

Поверхность подложки $\mathrm{GaAs}(111) \mathrm{B}$ (образец $F$ ) перед инициацией роста $\mathrm{GaSe}$ выдерживалась 4 мин в потоке 


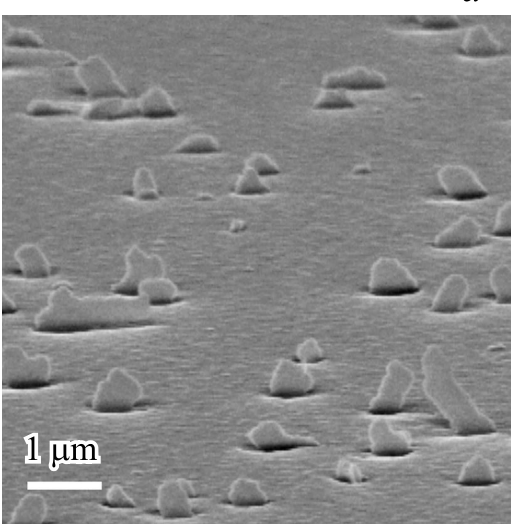

$b$

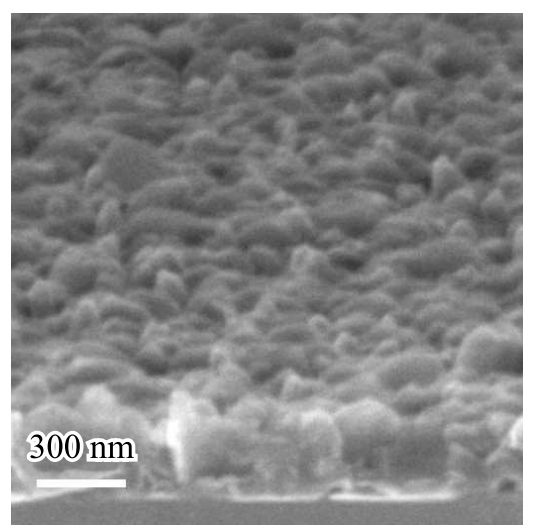

C

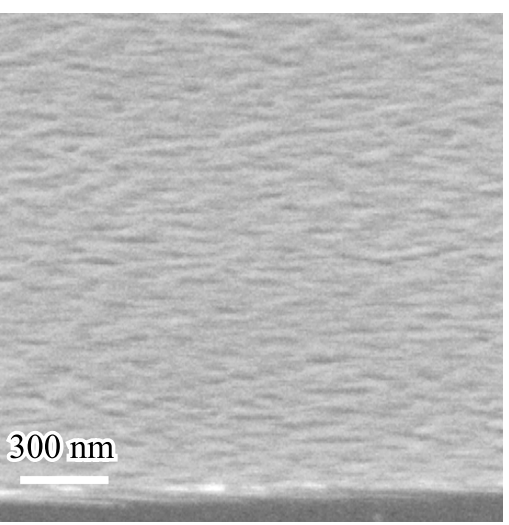

Рис. 1. Изображения поверхности слоев GaSe, полученных методом РЭМ: $a-$ образец $C, b-$ образец $D, c-$ образец $F$. Параметры МПЭ для каждого из образцов приведены в табл. 1.

Se. Образцы $E$ и $G$ были выращены в двухстадийном режиме [8], однако начальная стадия гетероэпитаксии осуществлялась при $T_{S}=400^{\circ} \mathrm{C}$.

Для исследования структурных характеристик образцов использовался метод просвечивающей электронной микроскопии (ПЭМ) в геометрии поперечного сечения (микроскоп Jeol JEM-2100F). Оценка толщин эпитаксиальных слоев $\mathrm{GaSe}$ и исследования морфологии поверхности проводились методом растровой электронной микроскопии (РЭМ) (микроскоп Camscan S4-90FE) в геометрии поперечного сечения и с поверхности образца. Информация о кристаллографической ориентации использованных подложек, а также об условиях роста методом МПЭ (соотношение потоков $\mathrm{Se} / \mathrm{Ga}$, температура подложки $\left.-T_{S}\right)$ и толщинах исследованных слоев GaSe приведена в табл. 1.

Измерения спектров ФО проводились на установке, описанной в работе [18]. В качестве источника модуляции использовался механически прерываемый высокостабильный фиолетовый $(\lambda=405$ нм) лазер SSP-DHS-405. При помощи синхронного детектирования (lock-in) регистрировалась интенсивность сформированного монохроматором зондового луча, отраженного от той же области образца, куда направлялся модулирующий лазер.

\section{3. Обсуждение результатов}

Морфология поверхности всех слоев $\mathrm{GaSe}$, выращенных при низкой температуре $\left(T_{S} \sim 400^{\circ} \mathrm{C}\right)$, выглядит приблизительно одинаково и характеризуется наличием на поверхности распределенных случайным образом так называемых „нанопластинок“ различных размеров и форм (рис. 1). При повышении температуры роста морфология поверхности становится более шероховатой, как было ранее показано в [8]. Однако ключевым фактором, оказывающим влияние на морфологию поверхности слоев GaSe, выращенных при одной и той же $T_{S}$, является не столько несоответствие условий роста стехиометрическим, сколько скорость осаждения слоя, определяемая потоком атомов $\mathrm{Ga}$. Изображения поверхности слоев GaSe (образцы $D$ и $F$ ), выращенных со скоростью роста $v_{\mathrm{GaSe}} \sim 0.5 \mathrm{HM} / \mathrm{Mин}(\mathrm{VI} / \mathrm{III} \sim 1)$ и $v_{\mathrm{GaSe}} \sim 5 \mathrm{Hм} / \mathrm{Mин}(\mathrm{VI} / \mathrm{III} \sim 6)$ соответственно, подтверждают эту закономерность.

Для выращивания ориентированных пленок с однородной толщиной была также предложена концепция двухстадийного роста [1], реализованная в данной работе при МПЭ образцов $E$ и $G$, выращенных на подложках $\operatorname{GaAs}(001)$ и $\mathrm{GaAs}(111) \mathrm{B}$ соответственно.

Изображения в геометрии поперечного сечения образца $C$ (толщина слоя GaSe $\sim 200 \mathrm{Hм}$ ), полученные методом ПЭМ, представлены на рис. 2. По картине электронной дифракции этого образца, приведенной ранее в работе [8], было установлено, что данный слой $\mathrm{GaSe}$ соответствует $\gamma$-политипу. Анализ изображения (рис. 2,a) позволяет сделать вывод о том, что слой $\mathrm{GaSe}$ состоит из доменов со средним латеральным размером $80-100$ нм.

На рис. 2, $b$ приведено ПЭМ-изображение высокого разрешения (ПЭМ ВР) гетероинтерфейса $\mathrm{GaSe} / \mathrm{GaAs}(001)$ образца $C$. Размытая граница между $\mathrm{GaSe}$ и GaAs может быть обусловлена как отжигом подложки GaAs в отсутствие потока As, так и образованием на гетерогранице переходного субмонослоя $\mathrm{Ga}_{2} \mathrm{Se}_{3}$ [19]. На изображении ПЭМ ВР отчетливо видна слоистая структура $\mathrm{GaSe}$, при этом период решетки в вертикальном направлении $\sim 0.8 \mathrm{Hм}$ соответствует толщине одного тетраслоя GaSe. Ось $c$ GaSe направлена по нормали к поверхности подложки $\mathrm{GaAs}(001)$. Наличие четко видимой границы (отмеченной стрелками на рис. $2, b)$ можно объяснить существованием повернутых на $30^{\circ}$ доменов в слое $\mathrm{GaSe}[20]$.

На рис. 3 приведен спектр ФО полуизолирующей подложки $\mathrm{GaAs}(001)$ и типичные спектры ФО интерфейсов $\mathrm{GaSe} / \mathrm{GaAs}(001)$ (образцы $A$ и $C$ ), измеренные вблизи энергии ширины запрещенной зоны GaAs 


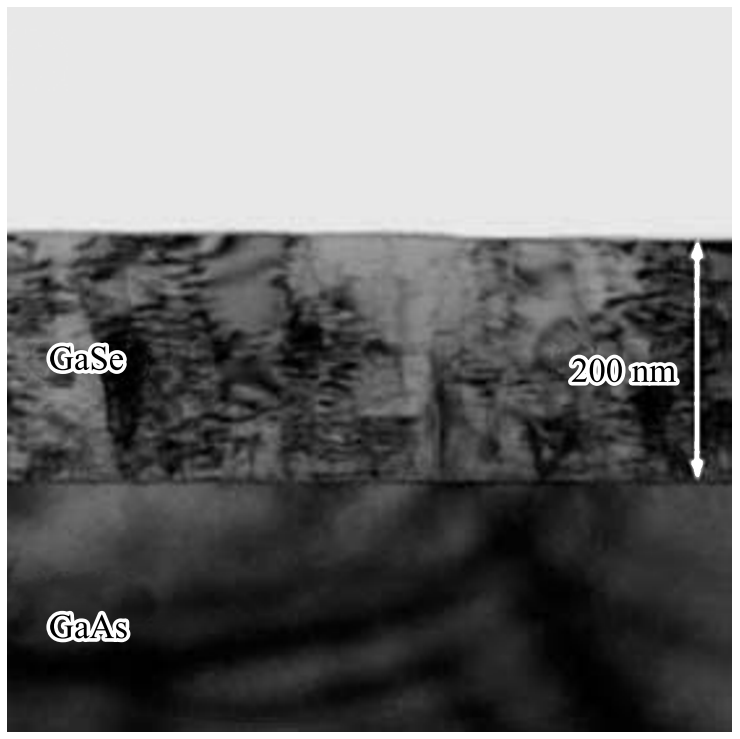

$b$

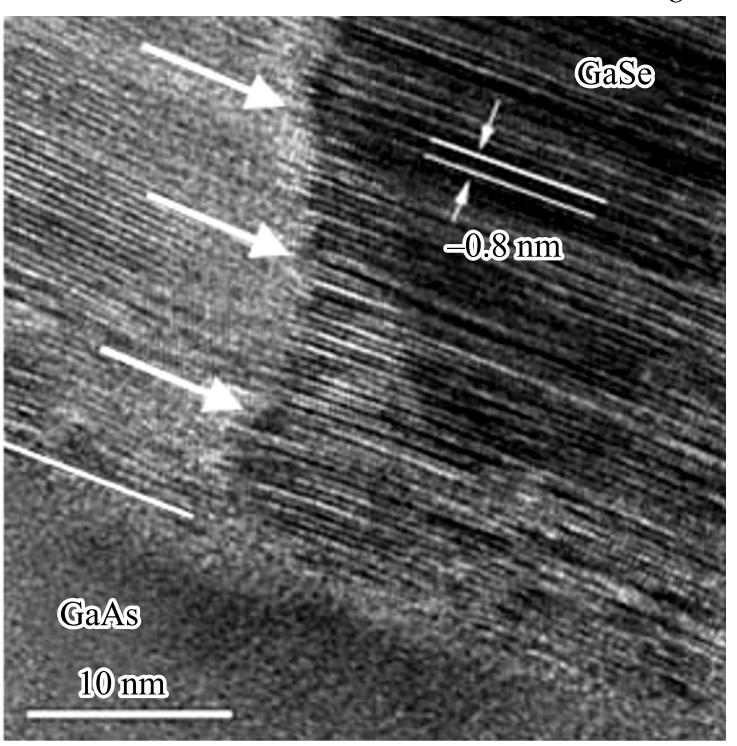

Рис. 2. $a-$ ПЭМ-изображение в поперечном сечении образца $C, b-$ изображение ПЭМ ВР этого же образца вблизи гетероинтерфейса $\mathrm{GaSe} / \mathrm{GaAs}(001)$.

$\left(E_{g}=1.424\right.$ эB). Отметим, что в данном случае рассматривается спектральная область, в которой GaSe прозрачен и, следовательно, сигнал ФО формируется именно в приинтерфейсной области GaAs. B спектре ФО полуизолирующей подложки $\mathrm{GaAs}(001)$ проявляется единичная осцилляция, что указывает на малую величину встроенного электрического поля (слабополевой режим) в приповерхностной области GaAs и хорошо согласуется с известными данными [21].

В образцах, выращенных непосредственно на подложке $\operatorname{GaAs}(001)$ (образцы $A$ и $C$ ), наблюдается уширение дифференциально-подобной спектральной линии вблизи $E_{g}$ арсенида галлия. Так, определенный трехточечным методом [22] параметр уширения (Г) спектра ФО полуизолирующей подложки $\mathrm{GaAs}(001)$ составлял 8.5 мэВ. При выращивании на еe поверхности слоя GaSe уширение увеличивалось до 13 и 16 мэВ для образцов $A$ и $C$ соответственно (табл. 2). Это уширение связано, по всей видимости, с наличием большого числа структурных дефектов вблизи гетероинтерфейса $\mathrm{GaSe} / \mathrm{GaAs}(001)$. Действительно, та же линия для структур со слоями $\mathrm{GaSe}$, выращенными на поверхности эпитаксиального буферного слоя $\mathrm{GaAs}(001)$ (образцы $D$ и $E$ ), уширена несколько меньше $(\Gamma=12$ мэВ). Следует отметить, что

Таблица 2. Определенные экспериментально параметр уширения спектров ФО (Г) и величина напряженности встроенного электрического поля (F) на интерфейсе исследуемых образцов $\mathrm{GaSe} / \mathrm{GaAs}(001)$

\begin{tabular}{c|c|c|c|c|c}
\hline Образец & $A$ & $B$ & $C$ & $D$ & $E$ \\
\hline$\Gamma$, мэВ & 13 & 13 & 16 & 12 & 12 \\
$\mathrm{~F}, \mathrm{BB} / \mathrm{cm}$ & 9.8 & 11.5 & 16.1 & 14.4 & 17.6
\end{tabular}

спектры ФО образцов $A$ и $C$ находятся практически в противофазе, что не влияет на дальнейшие оценки величины напряженности электрического поля. Фаза спектра отражения и, как следствие, ФО GaAs зависят от толщины прозрачного для зондирующего луча слоя $\mathrm{GaSe}$ на его поверхности из-за различной оптической длины пути отраженного луча.

Для образцов $\mathrm{GaSe} / \mathrm{GaAs}(001)$ режим ФО изменяется на среднеполевой. В этом случае напряженность встроенного электрического поля имеет относительно большое значение и на спектрах наблюдаются ОФК (рис. 3), экстремумы которых показаны стрелками. Период ОФК коррелирует с напряженностью встроенного электрического поля [23]: чем больше поле, тем больше период осцилляций. Таким образом, уже из общего вида формы линии спектров ФО можно сделать вывод, что образец $A$ имеет меньшее значение электрического поля в приинтерфейсной области GaAs по сравнению с образцом $C$. Образец $B$ (спектр ФО здесь не показан) характеризуется промежуточным значением электрического поля в приинтерфейсной области GaAs.

Ранее было показано, что при МПЭ другого селенсодержащего соединения - $\mathrm{ZnSe}-$ на подложках $\operatorname{GaAs}(001)$ при температуре роста $\sim 300^{\circ} \mathrm{C}$ наблюдается эффективная диффузия атомов $\mathrm{Se}$ в буферный слой $\mathrm{GaAs}$ на глубину до 10 нм [24]. Эпитаксиальный рост слоев $\mathrm{GaSe}$, рассматриваемых в данной работе, происходит при более высоких температурах $\left(400^{\circ} \mathrm{C}\right.$ и выше), что позволяет предположить наличие более глубокой диффузии атомов Se в GaAs. Кроме того, помимо температуры эпитаксиального роста, процесс диффузии атомов $\mathrm{Se}$ в GaAs (001) зависит от длительности процесса роста $(t)$ структуры, скорости осаждения материала и избыточного потока атомов $\mathrm{Se}$ на начальной стадии 


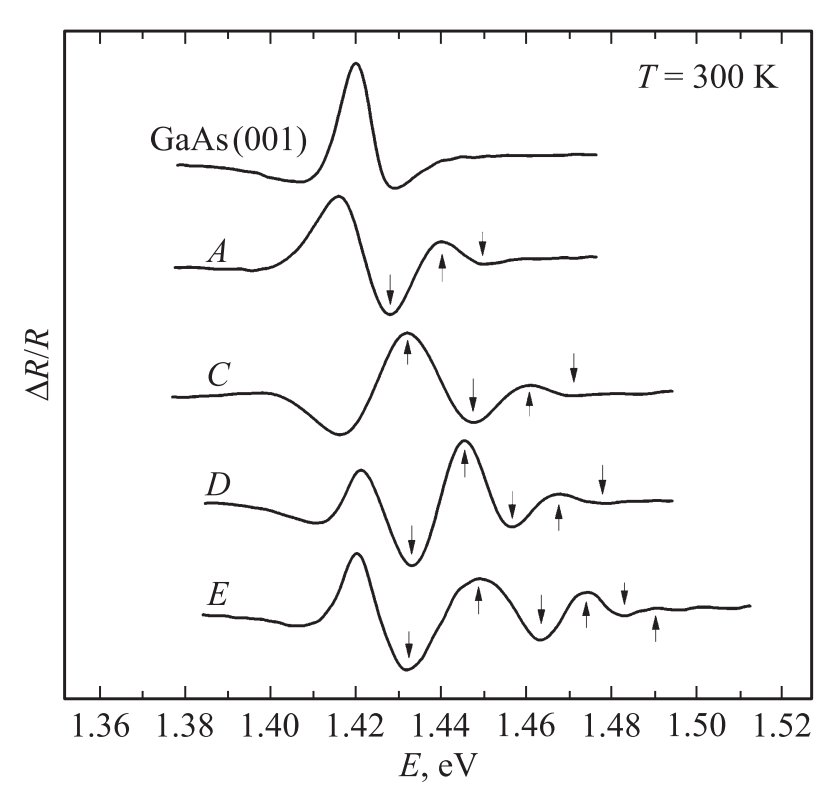

Pис. 3. Спектры ФО полуизолирующей подложки $\mathrm{GaAs}(001)$ (верхняя кривая), интерфейса $\mathrm{GaSe} / \mathrm{GaAs}(001)$, полученного при выращивании слоя GaSe непосредственно на подложке $\operatorname{GaAs}(001)$ (образцы $A$ и $C$ ), и интерфейса $\mathrm{GaSe} / \mathrm{GaAs}(001)$ для слоев $\mathrm{GaSe}$, осажденных на поверхности нелегированного буферного слоя $\mathrm{GaAs}$ толщиной 200 нм (образцы $D$ и $E$ ). Стрелками обозначены экстремумы ОФК, по периоду которых определялось значение напряженности встроенного электрического поля.

гетероэпитаксии (см. табл. 1). Однако влияние каждого фактора в отдельности оценить достаточно сложно.

Помимо диффузии Se вклад в величину наблюдаемых в работе встроенных электрических полей могут давать формирующиеся между $\mathrm{GaSe}$ и подложкой $\mathrm{GaAs}(001)$ переходные субмонослои, например слой $\mathrm{Ga}_{2} \mathrm{Se}_{3}[19,20]$, который образует химические связи с подложкой и заполняет поверхностные состояния GaAs.

В структурах $D$ и $E$, выращенных на эпитаксиальных буферных слоях GaAs (рис. 3), наблюдается большее число экстремумов ОФК, чем в случае роста $\mathrm{GaSe}$ непосредственно на подложках $\operatorname{GaAs}(001)$. Это можно объяснить тем, что рассматриваемый сигнал ФО формируется преимущественно в эпитаксиальном буферном слое $\mathrm{GaAs}$, характеризующемся более высоким структурным совершенством, чем подложка GaAs. Увеличение периода ОФК в образце $E$ по сравнению с образцом $D$, так же как и для образцов $A-C$, связано как с большей длительностью процесса роста, так и с увеличением соотношения падающих потоков $\mathrm{Se} / \mathrm{Ga}$ при МПЭ.

Напряженности поля были рассчитаны методом, подробно описанным в работе [25]. В работе [26] было показано, что период ОФК совпадает с периодом $\cos \left(2 / 3\left(\left(E-E_{g}\right) / \hbar \Omega\right)^{3 / 2}+\theta\right)$, где $\hbar \Omega-$ электрооптическая энергия, $\theta-$ фазовый фактор. Энергии экстремумов косинуса $\left(E_{j}\right)$, следующие после $E_{g}$, будут иметь индексы $j=1,2,3$ и т.д. Тогда, приравняв при $E=E_{j}$ аргумент приведенного выше косинуса значе- ниям $j \pi$, получим $\left(E_{j}-E_{g}\right)^{3 / 2}=3 / 2(\hbar \Omega)^{3 / 2}(j \pi-\theta)$. Таким образом, наклон $m$ прямой, построенной методом наименьших квадратов по точкам зависимости $\left(E_{j}-E_{g}\right)^{3 / 2}$ от номера $j$ экстремума ОФК, определяет электрооптическую энергию $\hbar \Omega \approx m^{2 / 3} / 2.81$ (мэВ). На рис. 4 приведены такие зависимости для образцов $D$ и $E$. Для обоих образцов взято одинаковое количество экстремумов. Напряженность встроенного электрического поля $\mathrm{F}$ вычисляется следующим образом: $\mathrm{F} \approx 3.24 \mu^{1 / 2}(\hbar \Omega)^{2 / 3}($ кВ/см $)$, где $\mu-$ приведенная эффективная масса в единицах массы свободного электрона $m_{0}$ (для GaAs $\mu=0.055 m_{0}$ [25]). Экспериментально определенные значения напряженности электрического поля для исследуемой серии образцов $\mathrm{GaSe} / \mathrm{GaAs}$ (001) приведены в табл. 2.

Максимальная погрешность произведенных измерений составила 0.7 кВ/см, при этом основной вклад в данную величину вносит точность определения значения высокоэнергетичных ОФК. Так как различие значений напряженности поля для данных образцов находится за пределами погрешности, в данной серии структур взаимодействие $\mathrm{GaSe}$ с подложкой (буферным слоем) происходит по-разному, что связано как с разным состоянием ростовой поверхности GaAs, так и с различными режимами МПЭ на начальной стадии гетероэпитаксии.

На спектрах ФО интерфейсов $\mathrm{GaSe} / \mathrm{GaAs}(111) \mathrm{B}$ (структуры $F$ и $G$ ) ОФК отсутствуют, что указывает на малые по величине значения встроенного поля на исследуемом гетероинтерфейсе (рис. 5). Это можно объяснить, например, более слабой диффузией атомов $\mathrm{Se}$ в подложку за счет того, что плоскость с кристаллографической ориентацией (111) является более плотно упакованной, чем $\operatorname{GaAs}(001)$ [27]. Еще одной причиной того, что в образцах $\mathrm{GaSe} / \mathrm{GaAs}(111) \mathrm{B}$ методом ФО было зарегистрировано более слабое приповерхностное поле, может являться уменьшение поверхностного изгиба зон

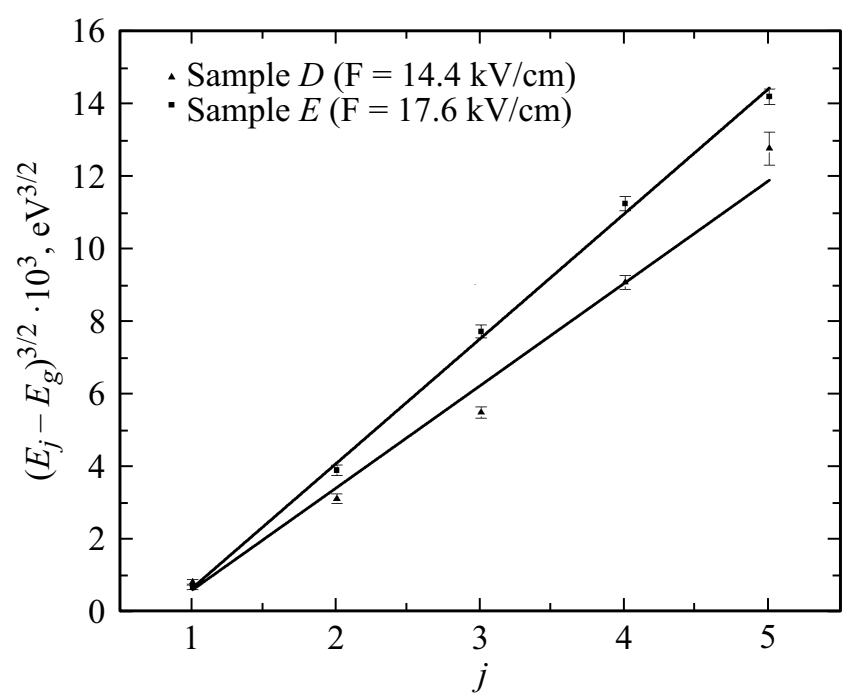

Рис. 4. Зависимость $\left(E_{j}-E_{g}\right)^{3 / 2}$ от номера экстремума $(j)$ ОФК для определения значений напряженности встроенного электрического поля (F) в образцах $D$ и $E$. 


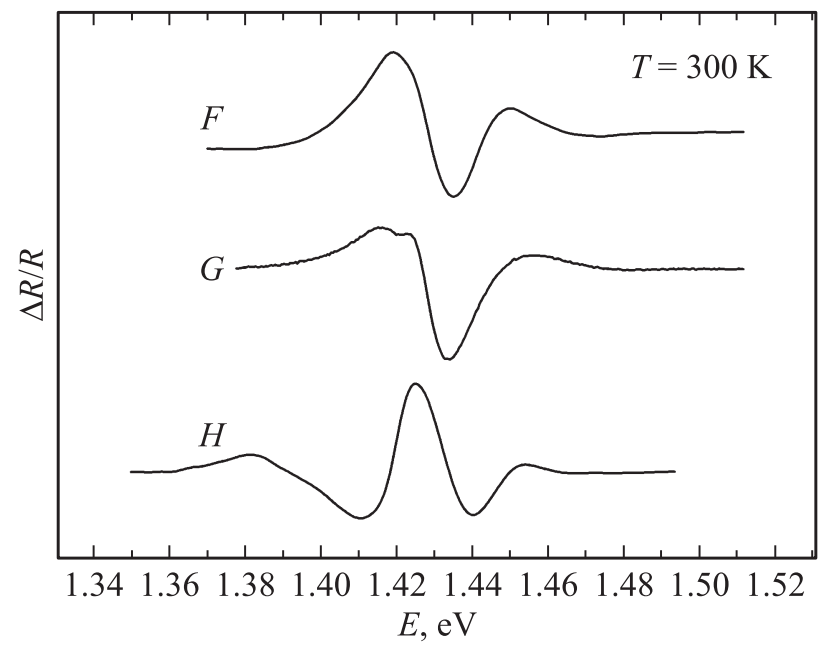

Рис. 5. Спектры ФО интерфейсов $\mathrm{GaSe} / \mathrm{GaAs}(111) \mathrm{B}$ (образцы $F$ и $G)$ и $\mathrm{GaSe} / \mathrm{GaAs}(112)$ (образец $H$ ).

на гетероинтерфейсе $\mathrm{GaSe} / \mathrm{GaAs}(111) \mathrm{B}$ по сравнению c $\mathrm{GaSe} / \mathrm{GaAs}(001)$, что подтверждается результатами, полученными методом рентгеновской фотоэлектронной спектроскопии $[28,29]$. Следует подчеркнуть, что предварительно проведенная пассивация поверхности подложки селеном с целью заполнения образующихся на поверхности кристалла оборванных связей (образец $F$ ) не приводит к появлению ОФК в спектрах $Ф О$, т.е. обменная реакция $\mathrm{Se}-\mathrm{As}$ в подповерхностных слоях незначительна. Согласно [29], атомы Se в таком случае замещают 3/4 монослоя атомов As на внешнем слое GaAs (111)B.

В случае гетероэпитаксии $\mathrm{GaSe} / \mathrm{GaAs}(111) \mathrm{B}$ нами не обнаружено упоминания в литературе об образовании переходных слоев, впрочем, как и для случая более редко встречающихся в литературе интерфейсов $\mathrm{GaSe} / \mathrm{GaAs}(112)$.

В спектре ФО образца $\mathrm{GaSe} / \mathrm{GaAs}(112)$ ОФК также не наблюдаются (рис. 5). Наблюдаемый в спектре ФО образца $H$ дополнительный пик в области энергии 1.38 эВ также присутствует в спектре ФО исходной полуизолирующей подложки $\mathrm{GaAs}(112)$. Наличие этого пика связано с отражением зондирующего луча от зеркальнополированной поверхности нерабочей стороны подложки и модуляцией собственного фотопоглощения $\mathrm{GaAs}$ с участием оптических фононов [30]. Следует отметить, что спектры ФО исходных полуизолирующих подложек с ориентациями (111)В и (112) в области ширины запрещенной зоны GaAs выглядели аналогично спектру, приведенному на рис. 3 для подложки $\mathrm{GaAs}(001)$.

\section{4. Заключение}

Таким образом, экспериментально показано, что при эпитаксии GaSe на подложках $\mathrm{GaAs}(111) \mathrm{B}$ и GaAs (112) встроенные электрические поля на интерфейсе не возникают. В случае подложки $\mathrm{GaAs}(001)$ в спектрах фотоотражения наблюдаются осцилляции ФранцаКелдыша, свидетельствующие о повышенной напряженности встроенных полей на интерфейсе, что может быть объяснено диффузией селена в глубь подложки и (или) образованием переходных слоев типа $\mathrm{Ga}_{2} \mathrm{Se}_{3}$. Само по себе взаимодействие поверхности подложки с селеном должно снижать изгиб энергетических зон вследствие заполнения поверхностных состояний и пассивации разорванных связей. Однако, диффундируя в глубь $\mathrm{GaAs}(001)$, селен может легировать приповерхностную область, из-за чего исходное малое по величине электрическое поле возрастает.

\section{Финрансирование работы}

Работа частично поддержана грантом РНФ (№ 18-7910161).

\section{Благодарности}

Авторы выражают благодарность Д.А. Кириленко за исследования, проведенные методом ПЭМ.

\section{Конфликт интересов}

Авторы заявляют, что у них нет конфликта интересов.

\section{Список литературы}

[1] M. Chen, H. Kim, D. Ovchinnikov, A. Kuc, T. Heine, O. Renault, A. Kis. npj 2D Mater. Appl., 2, 2 (2018).

[2] Z. Ben Aziza, V. Zólyomi, H. Henck, D. Pierucci, M.G. Silly, J. Avila, S.J. Magorrian, J. Chaste, Ch. Chen, M. Yoon, K. Xiao, F. Sirotti, M.C. Asensio, E. Lhuillier, M. Eddrief, V.I. Fal'ko, A. Ouerghi. Phys. Rev. B, 98, 115405 (2018).

[3] W. Huang, L. Gan, H. Li, Y. Ma, T. Zhai. Cryst. Eng. Commun., 18, 3968 (2016).

[4] D.J. Late, B. Liu, J. Luo, A. Yan, H.S.S. Ramakrishna Matte, M. Grayson, C.N.R. Rao, V.P. Dravid. Adv. Mater., 24, 3549 (2012).

[5] Y. Zhou, Y. Nie, Y. Liu, K. Yan, J. Hong, Ch. Jin, Yu Zhou, J. Yin, Zh. Liu, H. Peng. ACS Nano, 8, 1485 (2014).

[6] S. Lei, L. Ge, Zh. Liu, S. Najmaei, G. Shi, Ge You, J. Lou, R. Vajtai, P.M. Ajayan. Nano Lett., 13, 2777 (2013).

[7] P. Hu, Z. Wen, L. Wang, P. Tan, K. Xiao. ACS Nano, 6, 5988 (2012).

[8] С.В. Сорокин, П.С. Авдиенко, И.В. Седова, Д.А. Кириленко, М.А. Яговкина, А.Н. Смирнов, В.Ю. Давыдов, С.В. Иванов. ФТП, 53, 1152 (2019).

[9] A. Kuhn, A. Chevy, R. Chevalier. Phys. Status Solidi A, 31, 469 (1975).

[10] Ch.H. Lee, S. Krishnamoorthy, D.J. O’Hara, M.R. Brenner, J.M. Johnson, J.S. Jamison, R.C. Myers, R.K. Kawakami, J. Hwang, S. Rajan. J. Appl. Phys., 121, 094302 (2017).

[11] P.S. Avdienko, S.V. Sorokin, I.V. Sedova, D.A. Kirilenko, A.N. Smirnov, I.A. Eliseev, V.Yu. Davydov, S.V. Ivanov. Acta Phys. Polon. A, 136, 608 (2019).

[12] A. Koma. J. Cryst. Growth, 201/202, 236 (1999). 
[13] N. Kojima, K. Sato, M. Budiman, A. Yamada, M. Konagai, K. Takahashi, Y. Nakamura, O. Nittono. J. Cryst. Growth, 150, 1175 (1995).

[14] J.S. Hwang, C.C. Chang, M.F. Chen, C.C. Chen, K.I. Lin, F.C. Tang, M. Hong, J. Kwo. J. Appl. Phys., 94, 348 (2003).

[15] О.С. Комков, А.Н. Пихтин, Ю.В. Жиляев, Л.М. Фёдоров. Письма ЖТФ, 34, 81 (2008).

[16] X. Yin, H.M. Chen, F.H. Pollak, Y. Chan, P.A. Montano, P.D. Kirchner, G.D. Pettit, J.M. Woodall. J. Vac. Sci. Technol. A, 10, 131 (1992).

[17] D.E. Aspnes. Surf. Sci., 37, 418 (1973).

[18] О.С. Комков, А.Н. Пихтин, Ю.В. Жиляев. Матер. электрон. техн., 1, 45 (2011).

[19] Z.R. Dai, F.S. Ohuchi. Appl. Phys. Lett., 73, 966 (1998).

[20] Z.R. Dai, S.R. Chegwidden, L.E. Rumaner, F.S. Ohuchi. J. Appl. Phys., 85, 2603 (1999).

[21] А.Н. Пихтин, М.Т. Тодоров. ФТП, 27, 1139 (1993).

[22] T.J.C. Hosea. Phys. Status Solidi B, 189, 531 (1995).

[23] А.Н. Пихтин, О.С. Комков, К.В. Базаров. ФТП, 40 (5), 608 (2006).

[24] T.A. Komissarova, M.V. Lebedev, S.V. Sorokin, G.V. Klimko, I.V. Sedova, S.V. Gronin, K.A. Komissarov, W. Calvet, M.N. Drozdov, S.V. Ivanov. Semicond. Sci. Technol., 32, 045012 (2017).

[25] P.J. Hughes, B.L. Weiss, T.J.C. Hosea. J. Appl. Phys., 77, 6472 (1995).

[26] O.S. Komkov, G.F. Glinskii, A.N. Pikhtin, Y.K. Ramgolam. Phys. Status Solidi A, 206, 842 (2009).

[27] T. Scimeca, Y. Watanabe, R. Berrigan, M. Oshima. Phys. Rev. B, 46, 10201 (1992).

[28] L.E. Rumaner, M.A. Olmstead, F.S. Ohuchi. J. Vac. Sci. Techn. B: Microelectron. and Nanometer Struct. Processing, Measurement and Phenomena, 16 (3), 977 (1998).

[29] A. Ohtake, Sh. Goto, J. Nakamura. Scientific Rep., 8, 1220 (2018).

[30] А.Н. Пихтин, М.Т. Тодоров. ФТП, 28, 1068 (1994).

Редактор Г.А. Оганесян

\section{Investigation of built-in electric fields \\ at the GaSe/GaAs interface by photoreflectance spectroscopy}

O.S. Komkov ${ }^{1}$, S.A. Khakhulin ${ }^{1}$, D.D. Firsov ${ }^{1}$, P.S. Avdienko ${ }^{2}$, I.V. Sedova ${ }^{2}$, S.V. Sorokin ${ }^{2}$

${ }^{1}$ St. Petersburg Electrotechnical University „LETl“, 197376 St. Petersburg, Russia

2 loffe Institute,

194021 St. Petersburg, Russia

Abstract The built-in electric fields are generated at the $\mathrm{GaSe} / \mathrm{GaAs}$ heterointerface when GaSe layers are grown by molecular beam epitaxy on $\operatorname{GaAs}(001)$ substrates. The existence of these fields is indicated by the clearly observed Franz-Keldysh oscillations in the photoreflectance spectra. The different values of the intensities of these fields (within the $9.8-17.6 \mathrm{kV} / \mathrm{cm}$ range) can be associated both with the diffusion of Se atoms into the GaAs substrate (or into the GaAs buffer layer) and the formation of transition sub-monolayers at initial growth stages. No builtin fields were observed at the $\mathrm{GaSe} / \mathrm{GaAs}$ heterointerface in case of GaSe layers grown on $\mathrm{GaAs}(111) \mathrm{B}$ and $\mathrm{GaAs}(112)$ substrates, which can be explained by the lower efficiency of Se penetration into these substrates in contrast to $\mathrm{GaAs}(001)$. 